\title{
Antidepressants recruit new neurons to improve stress response regulation
}

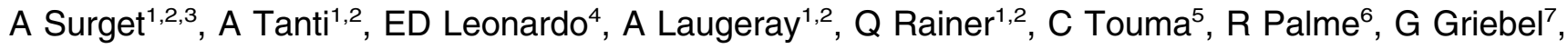 \\ Y lbarguen-Vargas ${ }^{1,2,3}, \mathrm{R} \mathrm{Hen}^{4}$ and C Belzung ${ }^{1,2}$ \\ ${ }^{1}$ U930 Imaging and Brain, Inserm, Tours, France; ${ }^{2}$ Université François Rabelais, Tours, France; ${ }^{3}$ Kavli Institute for Systems \\ Neuroscience \& Centre for the Biology of Memory, Norwegian University of Science and Technology (NTNU), Trondheim, \\ Norway; ${ }^{4}$ Departments of Psychiatry and Neuroscience, Columbia University, New York, NY, USA; ${ }^{5}$ Research Group of \\ Psychoneuroendocrinology, Max Planck Institute of Psychiatry, Munich, Germany; ${ }^{6}$ Department of Biomedical Sciences/ \\ Biochemistry, University of Veterinary Medicine, Vienna, Austria and ${ }^{7}$ Exploratory Unit, Sanofi-Aventis, Chilly-Mazarin, France
}

\begin{abstract}
Recent research suggests an involvement of hippocampal neurogenesis in behavioral effects of antidepressants. However, the precise mechanisms through which newborn granule neurons might influence the antidepressant response remain elusive. Here, we demonstrate that unpredictable chronic mild stress in mice not only reduces hippocampal neurogenesis, but also dampens the relationship between hippocampus and the main stress hormone system, the hypothalamo-pituitary-adrenal (HPA) axis. Moreover, this relationship is restored by treatment with the antidepressant fluoxetine, in a neurogenesis-dependent manner. Specifically, chronic stress severely impairs HPA axis activity, the ability of hippocampus to modulate downstream brain areas involved in the stress response, the sensitivity of the hippocampal granule cell network to novelty/glucocorticoid effects and the hippocampusdependent negative feedback of the HPA axis. Remarkably, we revealed that, although ablation of hippocampal neurogenesis alone does not impair HPA axis activity, the ability of fluoxetine to restore hippocampal regulation of the HPA axis under chronic stress conditions, occurs only in the presence of an intact neurogenic niche. These findings provide a mechanistic framework for understanding how adult-generated new neurons influence the response to antidepressants. We suggest that newly generated neurons may facilitate stress integration and that, during chronic stress or depression, enhancing neurogenesis enables a dysfunctional hippocampus to restore the central control on stress response systems, then allowing recovery.

Molecular Psychiatry (2011) 16, 1177-1188; doi:10.1038/mp.2011.48; published online 3 May 2011
\end{abstract}

Keywords: antidepressant; hippocampal neurogenesis; stress; depression; hypothalamopituitary-adrenal axis; immediate early gene

\section{Introduction}

In mammals, the hippocampus continues to generate new neurons in the dentate gyrus (DG) throughout adult life. ${ }^{1,2}$ Efforts directed at understanding the function of adult-generated neurons in the hippocampus have focused primarily on their role in cognitive processes such as contextual and spatial memory. There is also evidence linking adult neurogenesis to chronic stress, affective disorders and the response to antidepressant treatment. ${ }^{3-8}$ Indeed, stress, a major etiological factor for anxiety/depressive disorders, decreases the production and the survival of the

Correspondence: Dr A Surget, Kavli Institute for Systems Neuroscience \& Centre for the Biology of Memory, Norwegian University of Science and Technology (NTNU), MTFS (3rd Floor, Room 1314), Olav Kyrres Gate 9, Trondheim 7489, Norway.

E-mail: alexandre.surget@ntnu.no

Received 5 July 2010; revised 28 February 2011; accepted 22 March 2011; published online 3 May 2011 new hippocampal neurons, ${ }^{9,10}$ whereas treatments with antidepressants increase them ${ }^{4}$ and blocking hippocampal neurogenesis prevents the behavioral effects of antidepressants in several paradigms in rodents..$^{3,11-15}$ However, although there has been progress in elucidating the mechanisms through which stress reduces neurogenesis, little is known about either the function of these new neurons in triggering stress-related disorders or in the mechanisms through which they could exert some antidepressant effects.

The hippocampal formation is able to influence the activity of several cortical and subcortical structures involved in endocrine, motor, affective and cognitive functions. ${ }^{16-18}$ In addition to its role in strictly mnemonic processes, the hippocampus is therefore well positioned to modulate motivational behaviors, emotional states and stress responses. Particularly, the hippocampus is a regulator of the main neuroendocrine stress system, the hypothalamo-pituitaryadrenal (HPA) axis. ${ }^{19,20}$ It can modulate the activity 
of the paraventricular nucleus (PVN) of the hypothalamus (starter of HPA axis) through two- or three-neuron circuits. Indeed, hippocampal glutamatergic outputs project toward PVN-connected GABAergic neuron populations of stress-integrative subcortical regions such as lateral septum, anteromedial and posteromedial bed nucleus of stria terminalis (amBST and pmBST), medial and ventrolateral preoptic areas, dorsomedial and lateral hypothalamic nuclei (DMH and LH). ${ }^{21,22}$

Affective disorders have been frequently associated with abnormalities in HPA axis activity, ${ }^{23-25}$ including glucocorticoid hypersecretion and alterations of its negative feedback. ${ }^{26,27}$ These changes are probably important as it has been shown that the normalization of HPA axis activity parallels remission and reduces the risk of relapse in depressed patients with HPA axis abnormalities. ${ }^{28-31}$

The DG is exquisitely sensitive to glucocorticoid levels and may be damaged under conditions of high glucocorticoid levels and chronic stress. ${ }^{15,32,33}$ Within this framework, we hypothesized that the pro-neurogenic effect of the antidepressant fluoxetine (a selective serotonin reuptake inhibitor-SSRI) provides a fresh source of DG granule neurons highly responsive to environmental cues. As such, they are well positioned to initiate the improvement of hippocampal function in stress integration and perhaps, as a result, contribute to the antidepressant response when stress systems have been disturbed. For this purpose, we exposed mice with inhibited hippocampal neurogenesis to the unpredictable chronic mild stress (UCMS), an informative model to study stress-related disorders in animals, ${ }^{34,35}$ as it mimics the role of socio-environmental stressors in precipitating anxiety/depressive disorders, induces a syndrome reminiscent of the human neuropathology and reproduces the timeframe of the therapeutic response to antidepressants. ${ }^{33,34,36}$ Here, we found that chronic stress exposure induces severe abnormalities in the hippocampus-dependent regulation of stress systems and that antidepressant treatment with fluoxetine reverses such effects through a neurogenesis-dependent mechanism.

\section{Materials and methods}

A brief description of the materials and methods is presented in this section. For a full and detailed description, please refer to the Supplementary Information.

\section{Animals}

Male BALB/c mice were purchased from Taconic (Germantown, NY, USA) or from Centre d'Elevage Janvier (Le Genest Saint Isle, France) and were aged between 3 and 4 months at the time of the beginning of the UCMS exposure.

\section{UCMS}

The stress regimen used was previously described ${ }^{33}$ and is a variant of the chronic mild stress procedures described by Willner in rats. ${ }^{34}$ UCMS mice were repeatedly subjected to various socio-environmental stressors according to an unpredictable schedule for a total period of 6-8 weeks. From the third week of UCMS onward, mice were administered intraperitoneal (ip), once a day, with either vehicle, fluoxetine (20 $\mathrm{mg} \mathrm{kg}^{-1}$ per day) or SSR125543 $\left(20 \mathrm{mg} \mathrm{kg}^{-1}\right.$ per day). Treatment was always maintained until the end of the experiments. Body weight and coat state were assessed weekly, as markers of the progression of the UCMS-evoked syndrome. ${ }^{33,37}$

\section{Cookie test}

This test required a device containing three aligned compartments with the same dimension $(20 \times 20 \times 20 \mathrm{~cm})$. Only the colors of the walls and the floor were different between the compartments (Figure 2a). Mice were first familiarized with a chocolate cookie (Pepito, Lu, France) 4.5 weeks before the first testing. One hour before testing, the regular food was removed from the cage lid. At the time of testing, a small amount ( $2 \pm 1 \mathrm{~g}$ ) of chocolate cookie (or regular food in a control experiment) was placed at the center of the black compartment. The mouse was initially placed in the white compartment of the apparatus. Each session of the test lasted five minutes. The cookie consumption (\# bites) was recorded within the $5 \mathrm{~min}$ test period. Four sessions of testing were performed within 10 days (inter-test interval: 2 days).

\section{$X$-ray irradiation procedure}

Five weeks before UCMS, subsets of experimental animals were exposed to three targeted X-irradiations specifically above the hippocampus sparing the major part of the brain according to the procedure previously described..$^{3,11}$

\section{Immunohistochemistry}

Immunohistochemistry for subgranular zone (SGZ) proliferation was performed as previously described. ${ }^{11}$ Rat anti-BrdU antibody (1:500, Oxford Biotechnology, Oxfordshire, UK) was used as primary antibody followed by rabbit anti-rat biotinylated antibody (1:200, Vector Laboratories, Burlingame, CA, USA). To label Fos, immunohistochemistry was performed with a rabbit anti-Fos antibody (1:5000, PC38, Calbiochem, San Diego, CA, USA) followed by a donkey antirabbit biotinylated antibody (1:500, Jackson Immunoresearch Laboratories, West Grove, PA, USA). The staining was amplified with an avidin-biotin complex (Elite ABC kit, Vector Laboratories) and visualized with DAB (Sigma-Aldrich, St Louis, MO, USA).

For immunohistochemistry based on fluorescence labeling, the different primary antibodies used were as follows: mouse anti-NeuN monoclonal antibody (1:1000, Chemicon International, Billerica, MA, USA), rat antiBrdU monoclonal antibody (1:500 Oxford Biotechnology) and a rabbit anti-Fos monoclonal antibody (1:1000 Oxford Biotechnology); the secondary antibodies used were as follows: Alexa-488 nm anti-mouse, Alexa$546 \mathrm{~nm}$ anti-rabbit and Alexa-633 nm anti-rat antibodies (1:200, Molecular Probe, Eugene, OR, USA). 
Image analysis and cell quantification

When staining was visualized with $\mathrm{DAB}$, the number of positive cells was counted using $\times 20$ and $\times 40$ objective lens with a conventional light microscope. For Fos-labeled cell counting of subcortical regions, the nomenclature and nuclei boundaries used were those defined by Paxinos and Franklin's mouse brain atlas. ${ }^{38}$ Fos + cells within each region were counted bilaterally in consecutive sections starting from bregma 0.62 to bregma -1.58 . For each animal and region, the same number of sections was used and the volume of each area was controlled. Regions included and corresponding coordinates were as follows: lateral septum (bregma (0.62-0.14)), amBST (0.62-0.02), pmBST $(-0.10$ to -0.34$)$, anteroventral BST (0.62$0.02)$, ventrolateral preoptic area $(0.26$ to -0.10$)$, medial preoptic area $(0.14$ to -0.46$)$, DMH $(-1.34$ to -1.58), LH ( -0.34 to -0.70$)$ and PVN $(-0.58$ to -1.22$)$.

When staining was visualized with fluorochromelabeled secondary antibodies, the number of positive cells was counted using a $\times 40$ objective lens with a confocal or an epifluorescence microscope. Eight sections (16 hippocampus) along the rostro-caudal extent of the hippocampus were examined; bregma: $-1.46,-1.82,-2.18,-2.54,-2.80,-3.08,-3.28$, $-3.52 .^{38}$ We also counted the number of $\mathrm{NeuN}+/$ Fos + cells in the inner part of the GCL containing the SGZ (the two deepest rows of the GCL plus cells touching the last row at the interface with the hilus). ${ }^{39,40}$ Indeed, granule cells are produced throughout an outside-in gradient in the GCL, which results in a high proportion of young newborn neurons in the deepest rows bordering the hilus. ${ }^{41-44}$

\section{Quantification of corticosterone levels}

Fecal samples were analyzed for immunoreactive corticosterone metabolites using a $5 \alpha$-pregnane$3 \beta, 11 \beta, 21$-triol-20-one enzyme-immunoassay as previously described. ${ }^{45}$ Details regarding development, biochemical characteristics and physiological validation of this assay have previously been described. ${ }^{46,47}$ Plasma corticosterone levels was analyzed using a ${ }^{125}$ I-labeled corticosterone double-antibody radioimmunoassay kit (MP Biomedicals, Solon, OH, USA) according to the manufacturer's protocol.

\section{Dexamethasone (DEX) administration procedures}

DEX suppression test: mice were i.p. injected with either DEX-P (0.1 $\mathrm{mg} \mathrm{kg}^{-1}$, five mice per group) or saline $(0.9 \% \mathrm{NaCl}$, five mice per group). All fecalthe boli that were voided between 8 and $10 \mathrm{~h}$ after the injection were collected to measure the level of fecal corticosterone metabolites.

Sensitivity of granule cells to novelty and glucocorticoid effects: mice were i.p. injected with either DEX-P (0.1 mg kg-1, five mice per group) or saline $(0.9 \% \mathrm{NaCl}$, five mice per group). Thirty minutes later, mice were placed in a circular open-field (diameter $35 \mathrm{~cm}$ ) for $5 \mathrm{~min}$. Then, $90 \mathrm{~min}$ later (120 min after injection), mice were anesthetized with ketamine/xylazine (120 and $10 \mathrm{mg} \mathrm{kg}^{-1}$, respectively), transcardially perfused and their brains were collected for immunohistochemistry.

Intrahippocampal DEX infusion: the infusion procedure was derived from the method previously described. ${ }^{20}$ Mice were stereotaxically and bilaterally implanted with guide cannulas $(6 \mathrm{~mm}$ long, $0.6 \mathrm{~mm}$ outer diameter, $0.36 \mathrm{~mm}$ inner diameter). The following coordinates were used for the guide cannula implantation: $\quad$ bregma $=-3.08, \quad$ lateral $= \pm 2.3$, vertical $=-1.4 .^{38}$ After 1 -week recovery period from the surgery, infusion cannulas $(7 \mathrm{~mm}$ long, $0.3 \mathrm{~mm}$ outer diameter, $0.17 \mathrm{~mm}$ inner diameter) were placed and extended $1 \mathrm{~mm}$ below the guide cannulas. The animals received bilateral infusions during $1.5 \mathrm{~min}$ of either vehicle $(0.9 \% \mathrm{NaCl} / 0.2 \%$ ethanol) or $\mathrm{DEX}$ (50 ng in $0.6 \mu \mathrm{l}$ ). In one experiment, the brain was collected $2 \mathrm{~h}$ following the infusion to assess DEXinduced Fos changes in downstream brain structures and the PVN (Figure 3). In another experiment, the animals were killed by $\mathrm{CO}_{2}$ asphyxiation $4 \mathrm{~h}$ following infusion and trunk blood was collected to measure plasma corticosterone levels (Figure 6).

\section{Statistics}

Considering that relatively small sample sizes were used and that assumptions for parametric statistics could not be ensured (normality and homoscedasticity), data were analyzed using the non-parametric Kruskal-Wallis 'analysis of variance by ranks' H-test. Significant effects (that is, $P<0.05$ ) were followed-up with post-hoc tests (Holm-Bonferroni method) when appropriate. $P$-values that are indicated in the 'Results' section always derived from the betweengroups comparisons using the Kruskal-Wallis H-test, whereas $P$-values resulting from post-hoc comparisons are indicated in the figures.

\section{Results}

Hippocampal neurogenesis is required for chronic stress reversal by fluoxetine

We first assessed the involvement of hippocampal neurogenesis in the emergence and the recovery of behavioral and physical changes in the UCMS. For this purpose, mice were initially exposed to Xirradiations 5 weeks before UCMS procedure to ablate cell proliferation in the SGZ of the DG without affecting other neurogenic niches (Figure 1a). ${ }^{3,11}$ Mice were then subjected to a 6- to 8-week UCMS procedure or maintained under non-stressful conditions (control mice). Two weeks after initiating UCMS, mice were daily treated with either fluoxetine (20 $\mathrm{mg} \mathrm{kg}^{-1}$ per day, ip) or a vehicle solution (NaCl $0.9 \%$, ip). X-irradiation induced a strong depletion of SGZ cell proliferation ( $\sim 92 \%$, Figure 1b) independently of the environment (control/UCMS) or the treatment (vehicle/fluoxetine). UCMS exposure resulted in significant decreases of SGZ cell proliferation ( $\sim 27 \%$, Figure $1 \mathrm{~b})$ and 4-week-old newborn neurons ( $\sim 34 \%$, Supplementary Figure S1); these effects 

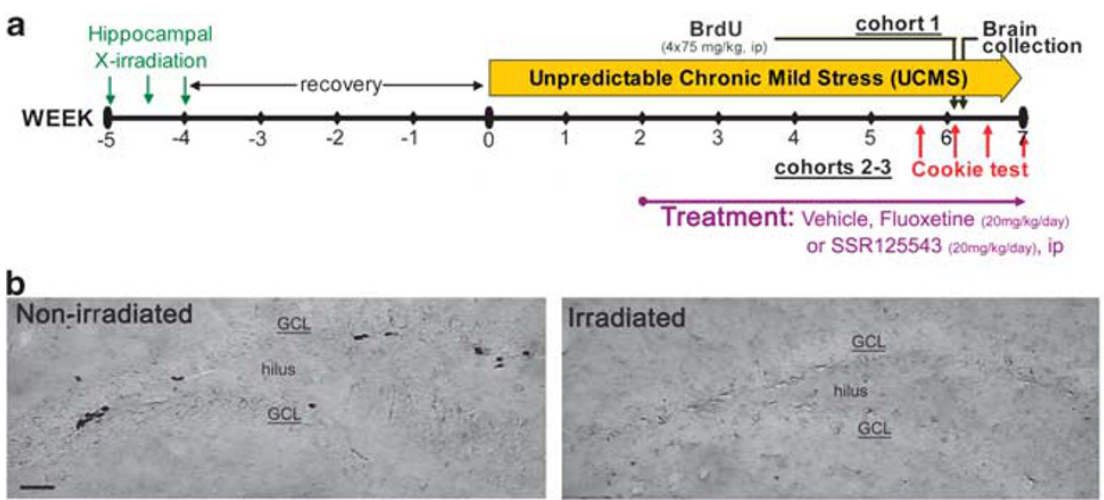

C

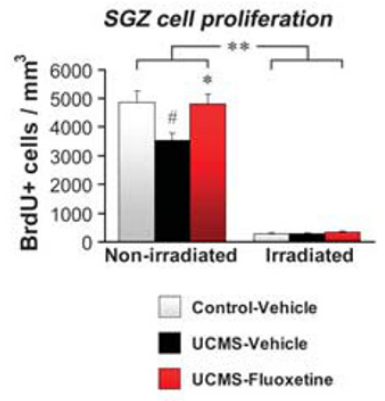

Figure 1 Focal hippocampal X-irradiation ablates cell proliferation in the subgranular zone (SGZ). (a) Schematic representation of the experimental design. A first cohort of mice was used to assess SGZ cell proliferation, see (b) and (c). Two other cohorts of mice were used for behavioral measures, see Figure 2. (b) Representative images of BrdU + cells ('black cells') in the SGZ (scale bar, $50 \mu \mathrm{m}$ ). (c) The cell proliferation assessed by the number of BrdU-positive cells per mm ${ }^{3}$ of the granule cell layer (GCL), $n=5-7$ per group. ${ }^{\sharp} P<0.05$ UCMS mice vs control-vehicle mice; ${ }^{*} P<0.05$ and ${ }^{* *} P<0.01$ UCMSfluoxetine mice vs UCMS-vehicle mice, or between line-connected groups. Data represent mean \pm s.e.m.
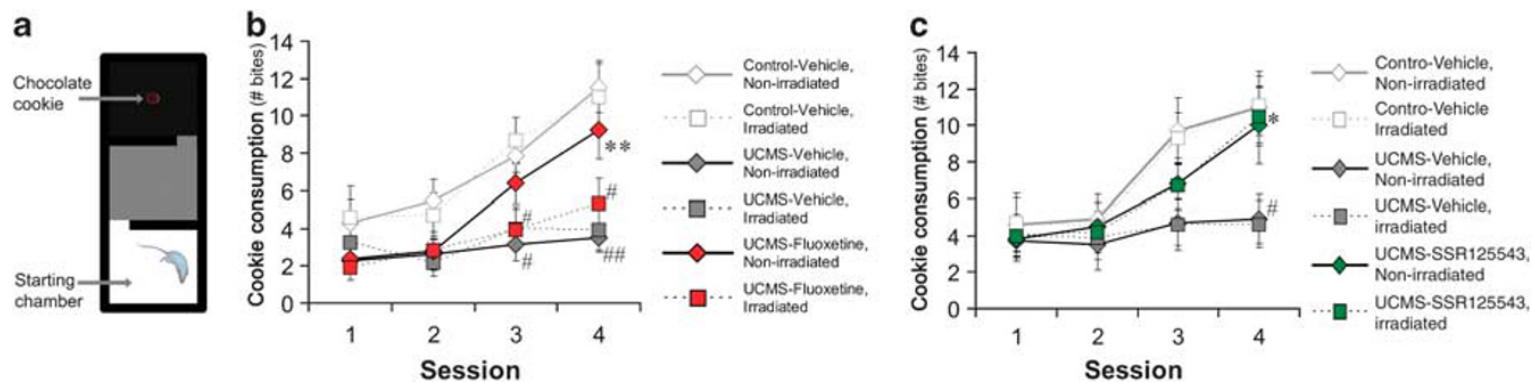

Figure 2 Hippocampal neurogenesis is required for the behavioral effects of fluoxetine but not of the corticotropin-releasing factor 1 antagonist SSR125543. (a) Schematic representation of the apparatus used for the Cookie test (CT). (b, c) The consumption of the cookie (number of bites) in the CT, $n=13-14$ per group for $(\mathbf{b})$ and $n=10$ per group for (c). ${ }^{\#} P<0.05$ and ${ }^{\# \#} P<0.01$ UCMS mice vs control-vehicle mice; ${ }^{*} P<0.05$ and ${ }^{*} * P<0.01$ UCMS-fluoxetine/SSR125543 mice vs UCMS-vehicle mice. Data represent mean \pm s.e.m.

were counteracted by chronic fluoxetine treatment (SGZ proliferation: $P<0.0001$; neurogenesis, $P=0.0082$ ).

Considering that anhedonia is one of the major symptoms of depression, we developed a behavioral paradigm based on the motivation for consuming a palatable stimulus (a chocolate cookie): the Cookie test. This test is based on the conflict between the drive for the stimulus and the neophobic behavior of the mouse. A reduction of the cookie consumption may therefore be interpreted as anhedonia, a habituation deficit or a combination of both effects. We found that session repetition resulted in a progressive increase of the cookie consumption in control mice (session 1, $P=0.8149$; session 2, $P=0.1387$; session 3 , $P=0.0013$; session $4, P=0.0001$; Figure $2 b$ ). UCMS exposure suppressed the consumption increase, an effect, which was reversed by fluoxetine treatment. Interestingly, although irradiated mice did not display any behavioral alterations in control or UCMS conditions, they were insensitive to the fluoxetine reversal. As a control experiment, the substitution of the cookie by a regular food pellet produced a quasi-null consumption during the four sessions for all the groups (data not shown), underlining the importance of the 'hedonic' feature of the stimulus. Our results indicate that the ablation of hippocampal neurogenesis on its own has no effect in the Cookie test but prevents the fluoxetine reversal in UCMS mice. Strikingly, similar results were also obtained when examining body weight change (another main symptom in major depression) and the coat state (Supplementary Figures S2a,b).

However, we found that 'antidepressant-like' effects can be obtained even in irradiated mice when using non-monoaminergic compounds such as the corticotropin-releasing factor 1 receptor $\left(\mathrm{CRF}_{1}\right)$ antagonist SSR125543. In a protocol similar to the previous experiment, SSR125543 $\left(20 \mathrm{mg} \mathrm{kg}^{-1}\right.$ per day, ip) also reversed neurogenesis reduction induced by UCMS $(P=0.018$; Supplementary Figure S1c). This compound counteracted UCMS effects in the Cookie test (session 1, $P=0.9998$; session 2, $P=0.8644$; session 3, $P=0.0714$; session $4, P=0.0108$; Figure 2c), on body weight and coat state (Supplementary Figure S2c,d) in non-irradiated mice but also in irradiated mice.

To summarize, hippocampal neurogenesis, although not directly involved in the emergence of a 
depression-like state or the vulnerability to stress, was required for the recovery effects of the monoaminergic antidepressant fluoxetine. On the other hand, alternative mechanisms, independent of neurogenesis, may be used to induce similar effects by the $\mathrm{CRF}_{1}$ antagonist, which directly target stress systems.

\section{Chronic stress impairs hippocampal modulation of brain areas involved in stress response}

Our previous results raise the possibility that stimulating neurogenesis by fluoxetine may facilitate the regulation of stress systems. We therefore assessed whether UCMS and fluoxetine affect the ability of the hippocampus to modulate the downstream subcortical relay sites regulating PVN activity (Figure 3a). For this purpose, mice were subjected to an intrahippocampal infusion with either the glucocorticoid receptor agonist DEX $(50 \mathrm{ng})$ or vehicle $(\mathrm{NaCl} 0.9 \%$, ethanol $0.2 \%$ ) (Figures $3 \mathrm{~b}$ and $\mathrm{c}$ ). We then evaluated the neuronal activation in the subcortical sites by immunodetection of Fos, product of an immediate early gene (Figure 3d). As a control, Fos expression was also quantified in the anteroventral BST, which regulates PVN activity but is devoid of direct hippocampal inputs. Intrahippocampal DEX infusion in control-vehicle mice was able to increase the number of Fos-labeled (Fos + ) cells in several of these subcortical relay sites: lateral septum $(P=0.0043)$, amBST $(P=0.0067)$, pmBST $(P=0.0014)$, medial preoptic area $(P=0.0275), \mathrm{DMH}$
$(P=0.0304)$ but not ventrolateral preoptic area $(P=0.124)$ and LH $(P=0.174)$ (Figure 3e, Supplementary Figure S3). UCMS impaired the DEX-induced increase of Fos + cells in the latter regions, whereas fluoxetine treatment counteracted the UCMS effects except in DMH. No effect of UCMS or treatment was found in the anteroventral BST $(P=0.157)$. We then tested if these effects can be reflected in the activation of the PVN itself. Indeed, intrahippocampal DEX infusion resulted in a significant increase of Fos expression in the PVN of UCMS-vehicle but not control-vehicle and UCMS-fluoxetine mice $(P=0.0391)$.

In summary, UCMS exposure greatly lessened the hippocampal regulation of the stress-integrative subcortical sites, an effect mainly counteracted by antidepressant treatment.

Chronic stress disrupts the sensitivity of the granule cell network to novelty/glucocorticoid effects

We then directly tested the ability of the DG granule neurons to react to glucocorticoids. These cells can be activated and express immediate early genes when individuals are exposed to a new environment. ${ }^{48-50}$ We took advantage of this property to examine the sensitivity of new and older granule cells to a new environment exposure following a single injection of DEX-P or vehicle (Figure 4a). For this purpose, we concurrently labeled cells for the neuronal marker NeuN, the immediate early gene product Fos
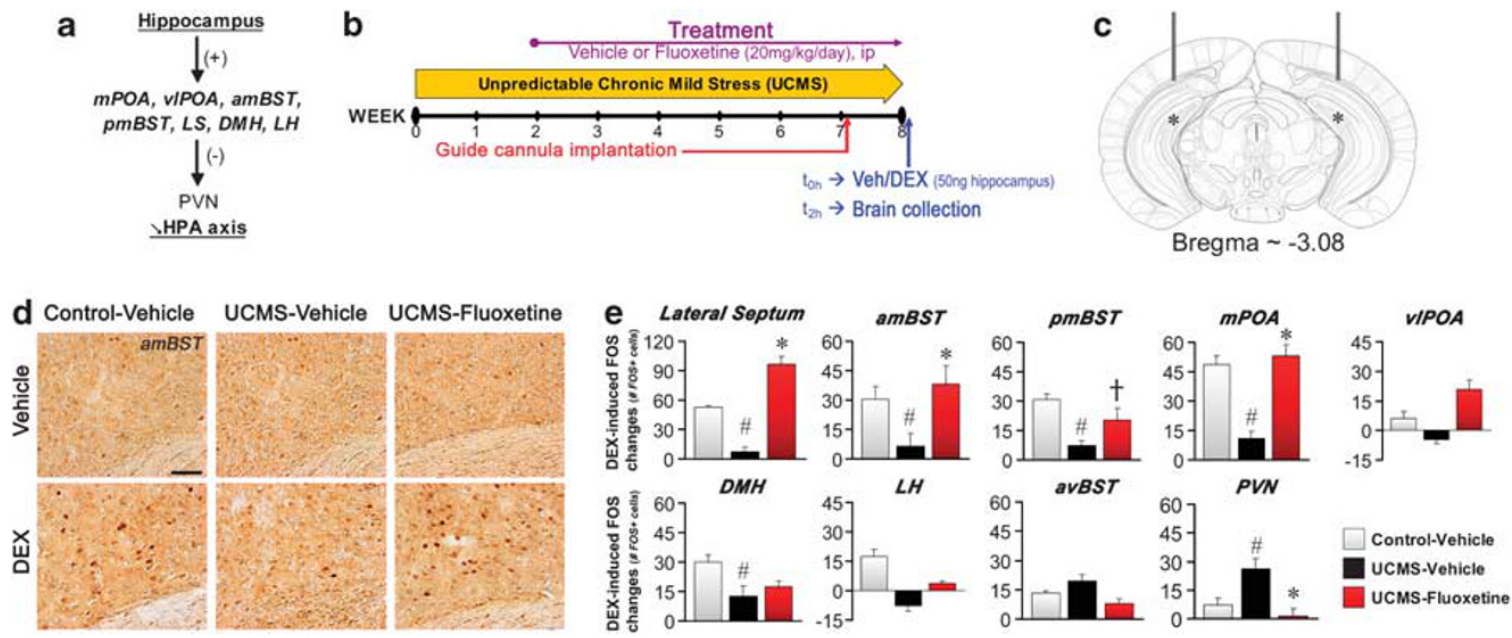

Figure 3 Chronic stress impairs hippocampal modulation of brain areas involved in the stress response, an effect reversed by fluoxetine. (a) Schematic representation of the neurocircuitry underlying hippocampal regulation of the hypothalamopituitary-adrenal (HPA) axis. Hippocampal CA1 and subiculum subregions send glutamatergic outputs $(+)$ toward subcortical relay sites, such as medial preoptic area (mPOA) and ventrolateral preoptic area (vlPOA), anteromedial and posteromedial bed nucleus of stria terminalis (amBST and pmBST), lateral septum (LS), dorsomedial and lateral hypothalamic nuclei (DMH and LH). These sites contain GABAergic neuron population (-) underlying inhibitory influences on the paraventricular nucleus (PVN). (b) Schematic representation of the experimental design. Veh and dexamethasone (DEX) mean vehicle and DEX, respectively. (c) Schematic representation of the guide-cannula implantation (bar: bregma $=-3.08$, lateral $= \pm 2.3$, vertical $=-1.4$ ) and of the DEX infusion sites, one millimeter lower (asterisk). The figure is adapted from Paxinos and Franklin $(2001){ }^{38}$ (d) Representative images of Fos + cells from the amBST (scale bar, $\left.50 \mu \mathrm{m}\right) .(\mathbf{e})$ Changes induced by intrahippocampal DEX infusion on the number of Fos + cells in LS amBST, pmBST, mPOA, vlPOA, $\mathrm{DMH}, \mathrm{LH}$, anteroventral BST (avBST) and PVN, $n=4$ per group. ${ }^{\#} P<0.05$ UCMS-vehicle mice vs control-vehicle mice; ${ }^{\dagger} P<0.1$ and ${ }^{*} P<0.05$ UCMS-fluoxetine mice vs UCMS-vehicle mice. Data represent mean \pm s.e.m. 

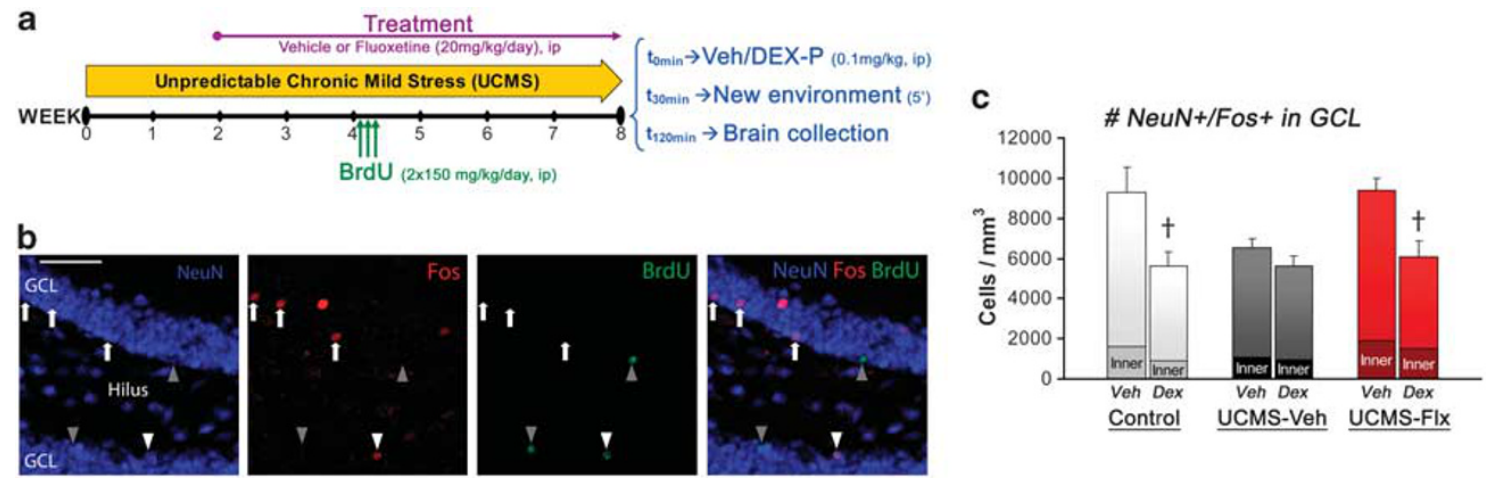

d \# NeuN+/BrdU+/Fos+ in GCL e

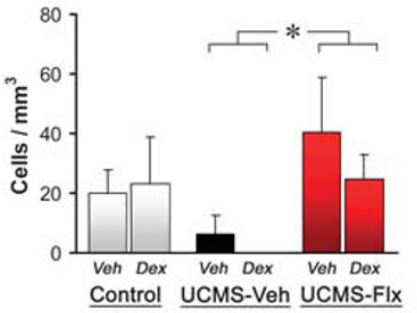

$\%$ of Fos+ in NeuN+ cells and BrdU+ cells

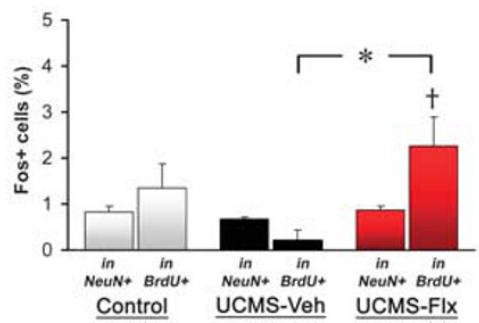

f

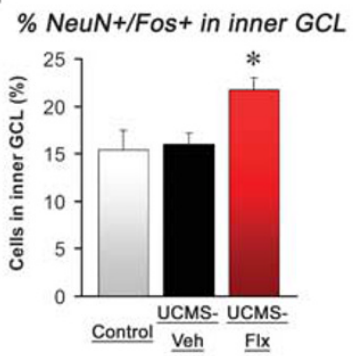

Figure 4 Chronic stress and fluoxetine alters the sensitivity of newborn and older hippocampal granule cells to novelty/ glucocorticoid effects. (a) Schematic representation of the experimental design. (b) Representative images of NeuN + (blue), Fos + (red), BrdU + (green) cells and colocalization (merged) in the granular cell layer (GCL) of the dentate gyrus (scale bar, $50 \mu \mathrm{m})$. Arrowheads show NeuN $+/$ BrdU + newborn neurons. NeuN $+/$ Fos + cells listed among cells belonging to the inner part of the GCL (including the SGZ) are indicated by white arrows (NeuN + /Fos + /BrdU- cells) or arrowhead (NeuN + / Fos + /BrdU + cells). (c) The figure shows the effects of novelty and dexamethasone on the recruitment of granule cells $\left(\mathrm{NeuN}+/\right.$ Fos + cells per GCL $\left.\mathrm{mm}^{3}\right), n=4-5$ per group. The dark part at the basis of each bar represents the proportion of $\mathrm{NeuN}+/$ Fos + cells listed in the inner part of the GCL. (d) The figure shows the effects of novelty and DEX on the recruitment of newborn granule cells (NeuN $+/$ Fos $+/$ BrdU + cells per GCL mm3), $n=4-5$ per group. (e) Proportion of Fos + cells $(\%)$ in NeuN $+/$ BrdU - cells and NeuN $+/$ BrdU + cells of the GCL, $n=8-10$ per group. (f) Proportion of the NeuN $+/$ Fos + cells listed in the inner part of the GCL, $n=8-10$ per group. ${ }^{\#} P<0.05$ UCMS-vehicle mice vs control-vehicle mice; ${ }^{*} P<0.05$ UCMS-fluoxetine mice vs UCMS-vehicle mice. ${ }^{\dagger} P<0.1$ Veh-treated mice vs DEX-treated mice or NeuN $+/$ BrdUcells vs NeuN + /BrdU + cells. DEX-P, dexamethasone-phosphate; Flx, fluoxetine; Veh, vehicle. Data represent mean \pm s.e.m.

('activated' granule cells) and the proliferation marker BrdU (4 week-old newborn cells) (Figure 4b).

We first assessed the effects on the whole granule cell population (Figure 4c, $P=0.0209$ ). Although UCMS-vehicle mice exhibited an apparent lower $\mathrm{NeuN}+/$ Fos + cell density than the other mice, we did not obtain any significant difference of neuronal activation in response to novelty between the three groups. On the other hand, a single DEX administration produced a trend to reduce the density of $\mathrm{NeuN}+/ \mathrm{Fos}+$ cells in the GCL of the control mice $(\sim 39 \%)$. Such a reduction was not found in UCMSvehicle mice ( $\sim 11 \%)$, in contrast to UCMS-fluoxetine mice $(\sim 35 \%)$.

We then focused on the newborn 4-week-old neurons by assessing the density of $\mathrm{NeuN}+1$ BrdU $+/$ Fos + cells in the GCL (Figure 4d, $P=0.0198)$. No effect of DEX was found in any group. Although no difference appeared between controlvehicle and UCMS-vehicle mice, fluoxetine significantly increased the density of $\mathrm{NeuN}+/ \mathrm{BrdU}+/$ Fos + cells in UCMS mice. However, it cannot be excluded that this effect reflects only the difference in neurogenesis levels between UCMS-vehicle and
UCMS-fluoxetine (Supplementary Figure 1b). We therefore aimed to validate the latter result by calculating the rate of Fos + in both NeuN + cells and $\mathrm{NeuN}+/ \mathrm{BrdU}+$ cells (Figure 4e, $P=0.0226$ ). Again, fluoxetine significantly increased the rate of $\mathrm{NeuN}+/ \mathrm{BrdU}+$ cells expressing Fos in UCMS mice $(2.26 \pm 0.62$ in UCMS-fluoxetine vs $0.22 \pm 0.22$ in UCMS-vehicle) and even yielded to a trend for higher proportions of Fos + cells in young newborn neurons $(0.86 \pm 0.1$ for NeuN + cells), contrasting with both control-vehicle and UCMS-vehicle mice.

However, the low frequency of Fos expression throughout the GCL, along with the lower neurogenesis level in UCMS-vehicle mice, might prevent reliable statistical comparisons by decreasing the chance to meet triple labeling cells in these mice. As a result, it is possible that differences between UCMS-vehicle and UCMS-fluoxetine mice have been artificially overstated (although it should also occur with control mice, which was not the case). To obtain data from a broader population of newborn neurons, we analyzed the proportion of NeuN $+/ \mathrm{Fos}+$ in the inner part of the GCL containing the SGZ and high proportion of young neurons (Figure 4b). This 
analysis showed that UCMS-fluoxetine mice hold a greater proportion of Fos + cells $(\sim 21 \%)$ than control-vehicle $(\sim 15 \%)$ and UCMS-vehicle mice ( $\sim 16 \%$ ) (Figures 4c-f; $P=0.0186$ ), confirming our previous results with the BrdU labeling.

In summary, UCMS exposure decreased the sensitivity of the GCL network to the combined novelty/ glucocorticoid effects. Fluoxetine was able to counteract this effect by recruiting higher proportions of newborn granule cells.

\section{Fluoxetine restores HPA axis negative feedback via a neurogenesis-dependent mechanism}

To examine more deeply the link between hippocampal neurogenesis and stress response, we investigated whether ablation of neurogenesis and UCMS induce abnormalities in the HPA axis similar to those found in anxiety/depressive disorders. A repeated collection of fecal samples across $33 \mathrm{~h}$ was performed on mice previously exposed to a 7-week UCMS (Figure 5a and b). Slight but significant effects of UCMS were reported on the circadian activity of the HPA axis, and fluoxetine partially reverse these effects in nonirradiated mice (Supplementary Figure S4). We then examined the integrity of the negative feedback of the HPA axis through the DEX suppression test. In this test, the administration of the glucocorticoid receptor agonist DEX-P $\left(0.1 \mathrm{mg} \mathrm{kg}^{-1}\right.$, ip) is known to suppress the subsequent release of endogenous glucocorticoids in the plasma when negative feedback integrity is undamaged. UCMS dampened the effectiveness of the negative feedback (control $\sim 61 \%$ vs UCMS $\sim 38 \%$ ) whereas fluoxetine restored DEXinduced suppression to control levels $(\sim 66 \%)$ (Figure 5c, $P=0.016$ ). However, although ablation of hippocampal neurogenesis did not significantly affect the negative feedback integrity in control $(\sim 60 \%)$ and UCMS $(\sim 30 \%)$ vehicle-treated mice, it significantly attenuated the improvement of the HPA axis negative feedback in UCMS mice by fluoxetine treatment $(\sim 42 \%)$.
New neurons contribute to the hippocampal inhibition of the stress response

Our latter results support the idea that neurogenesis may subserve some stress integration roles of the hippocampus. To precisely determine the role of the new neurons on hippocampus-dependent regulation of the stress response, we examined the ability of the hippocampus to regulate HPA axis activity under UCMS conditions and assessed how antidepressant treatment and neurogenesis can affect this function. Following UCMS exposure, mice were bilaterally implanted with guide cannulas above the DG (Figures $6 \mathrm{a}$ and b) and injected with either DEX (50 ng) or vehicle ( $\mathrm{NaCl} 0.9 \%$, ethanol $0.2 \%$ ). The results demonstrated that the intrahippocampal DEX infusion induced $51.2 \%$ plasmatic corticosterone suppression in non-irradiated control mice $(P=0.0034$; Figure 6c, Supplementary Figure S5). The neurogenesis ablation did not alter on its own the ability of the hippocampus to inhibit the HPA axis, as suggested by the $50.9 \%$ DEX-induced corticosterone suppression in irradiated control mice. However, UCMS disrupted hippocampal inhibition with low suppression in both non-irradiated and irradiated mice (5.1 and 3.7\%, respectively). Finally, fluoxetine was able to restore hippocampus-dependent negative feedback on the HPA axis in non-irradiated UCMS mice to control levels (56.1\%), but not in irradiated UCMS mice $(12.4 \%)$. This latter result indicates that fluoxetine requires new hippocampal neurons to re-establish the hippocampal inhibition of the HPA axis under chronic stress conditions.

\section{Discussion}

Since the first reports linking the behavioral effects of antidepressants to hippocampal neurogenesis, there has been little progress in understanding the specific role of neurogenesis in antidepressant response. Accordingly, it was necessary to identify hippocampal functions that could be affected by adding supplemental new neurons and then contribute to
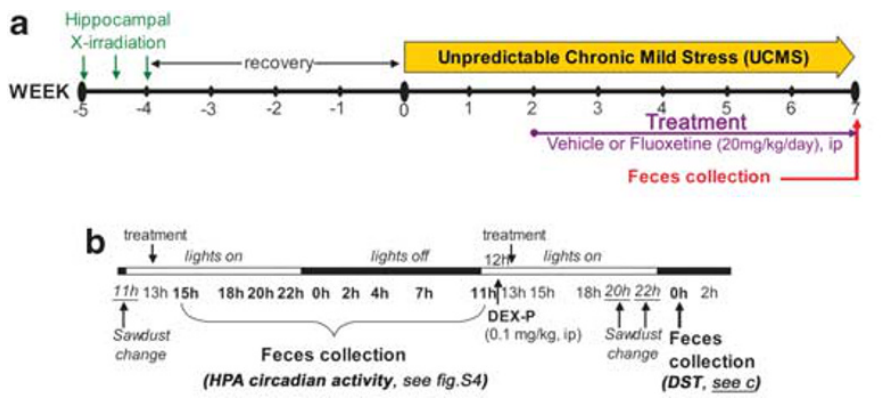

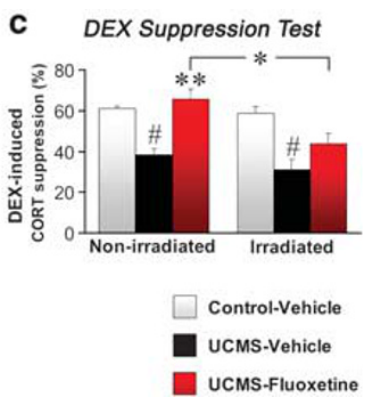

Figure 5 Fluoxetine-induced improvement of the HPA axis negative feedback under chronic stress conditions involves hippocampal neurogenesis. (a) Schematic representation of the experimental design. (b) Schedule of the fecal sample collection and of the dexamethasone-phosphate (DEX-P) administration. (c) The DEX suppression test allowed assessing the integrity of the HPA axis negative feedback. The figure shows the DEX-induced suppression of fecal corticosterone metabolites (CORT), $n=8-11$ per group. ${ }^{\#} P<0.05$ UCMS-vehicle mice vs control-vehicle mice; ${ }^{*} P<0.05$ and ${ }^{*} P<0.01$ UCMS-fluoxetine mice vs UCMS-vehicle mice, or between line-connected groups. Data represent mean \pm s.e.m. 

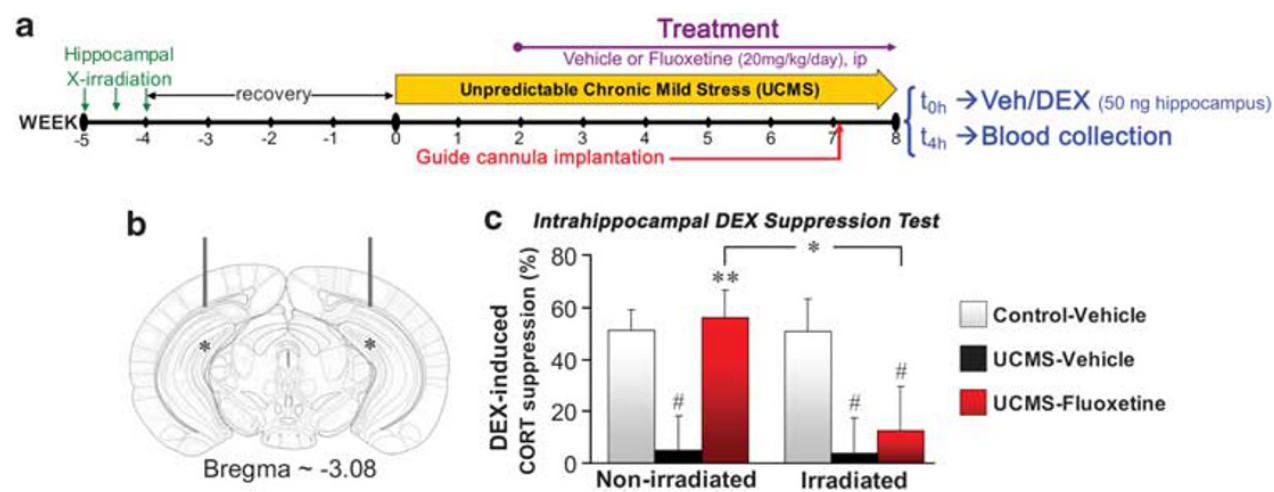

Figure 6 Adult-generated granule neurons are required to restore the hippocampal inhibition of the hypothalamo-pituitaryadrenal axis under chronic stress conditions. (a) Schematic representation of the experimental design. (b) Schematic representation of the guide-cannula implantation (bar: bregma $=-3.08$, lateral $= \pm 2.3$, vertical $=-1.4$ ) and of the dexamethasone (DEX) infusion sites, one millimeter lower (asterisk). The figure is adapted from Paxinos and Franklin (2001).$^{38}$ (c) An intrahippocampal DEX suppression test has been used to test the ability of hippocampus to inhibit the HPA axis. The figure shows the corticosterone (CORT) suppression induced by intrahippocampal DEX infusion, $n=7-8$ per group. ${ }^{\#} P<0.05$ UCMS mice vs control-vehicle mice; ${ }^{*} P<0.05$ and ${ }^{*} P<0.01$ UCMS-fluoxetine mice vs UCMS-vehicle mice, or between line-connected groups. Veh, vehicle; DEX, dexamethasone. Data represent mean \pm s.e.m.

recovery following chronic stress and anxiety/depression-like states. We have identified such functions in this study. Our findings reveal that chronic stress exposure severely disrupts HPA axis activity, hippocampal regulation of subcortical stress-integrative structures, sensitivity of the granule cell network to combined novelty/glucocorticoid effects and hippocampus-dependent negative feedback of the HPA axis. Furthermore, we demonstrate that the SSRI fluoxetine uses neurogenesis-dependent mechanisms to restore hippocampal control over stress systems as well as to reverse the behavioral and physical effects of UCMS. Taken together, these results provide direct evidence for a neurobiological process through which neurogenesis participates to antidepressant response: new neurons are recruited by antidepressant drugs to reestablish hippocampal regulation of stress systems, which in turn could initiate recovery.

There has been much discussion about a possible causative role for adult neurogenesis in anxiety/ depression. ${ }^{51-54}$ Our results do not support such a possibility. First, in line with previous studies, the ablation of adult-generated hippocampal neurons does not cause any anxiety/depression-like states (but see ref. 7),,$^{3,12-15,55-58}$ or increases vulnerability to chronic stress. ${ }^{11}$ Second, enhancing neurogenesis is unlikely to be the final process through which recovery becomes possible. Indeed, although we confirmed that hippocampal neurogenesis is required for the reversal of the behavioral and physical effects of UCMS by monoaminergic antidepressants (fluoxetine and imipramine), ${ }^{11}$ we also established that a similar reversal can be elicited even in animals with ablated neurogenesis by compounds targeting directly stress response circuits $\left(\mathrm{CRF}_{1}\right.$ or vasopressin $1 \mathrm{~b}$ antagonists). ${ }^{11}$ As a consequence, elevations of hippocampal neurogenesis may be a crucial but indirect pathway through which monoaminergic antidepres- sants exert effects on downstream structures and then underlie recovery.

We previously showed that fluoxetine required hippocampal neurogenesis to reverse UCMS effects in standard behavioral tests, such as the NoveltySuppressed Feeding (NSF) test. ${ }^{11}$ It is noteworthy that we extend here such results to alterations more relevant for depressive disorders, such as anhedonia or body weight changes. ${ }^{59}$ This is critical as it has recently been shown that not all tests sensitive to the behavioral effects of antidepressants might involve neurogenesis-dependent mechanisms. ${ }^{15}$ Moreover, the neurogenesis-dependence seems to emerge only under chronic stress or corticosterone treatment for mouse strains such as C57BL/6 or BALB/C. ${ }^{11,15}$ In contrast to chronically stressed mice, ${ }^{11,37}$ fluoxetine may induce some behavioral effects independent of neurogenesis and fail to alter neurogenesis in unstressed BALB/C mice. ${ }^{58,60}$ Considering that antidepressants are mainly devoid of mood-changing effects in non-depressed healthy humans ${ }^{61-63}$ and that fluoxetine effects on behavior and large-scale gene expression greatly differ depending if the mice are under control or UCMS conditions, ${ }^{33}$ paradigms elaborated in 'non-depressed' mice may engage different neurobiological mechanisms that are perhaps irrelevant to clinical remission. Rather, it is likely that relevant antidepressant effects are conditional on the presence of a disorder-related neuropathology. ${ }^{36}$ In the same vein, antidepressant effects that arise during treatment shorter than 14 days are obviously assumed to be neurogenesis-independent. ${ }^{56,58,64}$ Indeed, antidepressants require more than 1 week to significantly increase SGZ cell proliferation ${ }^{3,4}$ and it takes 1-2 weeks for new cells to start to integrate into the network. ${ }^{65}$ This timeframe suggests that at least $2-3$ weeks should be expected before the neurogenic effects of antidepressants can significantly impact the DG network if so. It is noteworthy that this delay parallels 
the course of the physical and behavioral effects of fluoxetine in the UCMS model. ${ }^{11,33,45}$ This temporal correlation strengthens the idea that neurogenesis may be required for fluoxetine to reverse UCMSinduced effects. Interestingly, this timeframe also parallels the delay before the first beneficial effects in patients with major depression, ${ }^{66}$ suggesting that neurogenesis could also be involved in antidepressant effects in humans. The two first studies investigating the relationship between hippocampal neurogenesis and antidepressant drugs in depressed patients have yielded mixed results: an increase of the SGZ neural progenitors was found after antidepressant treatment in adult, but not elderly patients. ${ }^{5,6}$

One meaningful finding of our study is that, without hippocampal neurogenesis, fluoxetine becomes unable to restore under chronic stress conditions the hippocampus-dependent inhibition of the HPA axis as well as to reverse the behavioral and physical alterations. This suggests that the improvement of stress system regulation is a critical process in the therapeutic action of antidepressants, at least in the substantial subset of patients with altered HPA axis reactivity. This is consistent with clinical data which demonstrate that, in most patients with altered HPA axis negative feedback, remission and decreased risk of relapse are associated with the improvement of HPA axis functioning. ${ }^{28-31}$ Overall, this finding reveals that the hippocampus not only regulates brain systems involved in the stress response at baseline but is also critical in mediating the ability of monoaminergic antidepressants to modulate stress response, probably through newly generated neurons. This possibility is in agreement with a brief report indicating that neurogenesis inhibition may yield higher corticosterone secretion in mice following exposure to a new bright-light condition, suggesting that even under conditions when the negative feedback is not fully desensitized, newborn neurons may have a more subtle role in dampening the response to stress. ${ }^{67}$

As a consequence, we aimed to scrutinize precisely the relationships between the hippocampus and stress response systems. Specifically a single preadministration of the synthetic glucocorticoid DEX decreased Fos expression in the GCL of controlvehicle mice exposed to a new context. These differences in granule cell activation could potentially influence the activity of the next hippocampal cell layer (CA3) ${ }^{68}$ and then enable the hippocampal network to couple stress and contextual information. ${ }^{69}$ Hence, a possible interpretation is to consider this reduction as a manner for the granule cell population to take into account, at the network level, glucocorticoid releases during new contextual inputs. On the other hand, this Fos-induction produced by novelty is disrupted under chronic stress with no additional effect of exogenous glucocorticoids. It is therefore conceivable that the alteration of the GCL sensitivity leads to disturbances in information processing and stress integration. We tested this possibility by probing the neurocircuitry connecting the hippocampus to the HPA axis. ${ }^{21,22}$ Our results demonstrate that chronic stress profoundly moderates the hippocampal influence on subcortical structures involved in the stress response such as lateral septum, BST, preoptic area and DMH. Taken together, these results suggest that chronic stress, by decreasing inhibitory regulation from the hippocampus, may bias the net input balance toward greater excitatory influences into the PVN leading to its overactivation and perhaps underlying the impairments of the hippocampus-dependent negative feedback on the HPA axis.

Strikingly, the Fos induction in the GCL and the response to exogenous glucocorticoids are preserved in fluoxetine-treated UCMS mice. Antidepressant treatment is therefore able to restore under chronic stress conditions the sensitivity of the granule cell network to novelty/glucocorticoid effects. As adultgenerated granule cells are continuously added to the network, they are a potential source of new sensitive neurons with enhanced plasticity and excitability. ${ }^{57,70-74}$ Considering that fluoxetine treatment increased neurogenesis levels in UCMS mice, it was then conceivable that such compounds compensate the chronic stress effects on GCL network activity by recruiting higher proportions of adult newborn neurons among the granule cells expressing Fos. Indeed, this hypothesis was confirmed in UCMSfluoxetine mice with a greater density of 4-week-old newborn cells expressing Fos and a higher rate of Fos + neurons in the inner GCL (containing high levels of newborn young neurons). ${ }^{41-44}$ Enhancing neurogenesis may thus be a way for antidepressant drugs to add a fresh source of new sensitive neurons that may affect hippocampal functioning and then improve stress integration.

Interestingly, the proportion of Fos expression in the inner GCL of UCMS-fluoxetine mice are even greater than in control-vehicle mice, which also exhibited high levels of SGZ cell proliferation and neurogenesis. A potential explanation is that fluoxetine does not only enhance neurogenesis but also accelerates maturation and synaptic integration of the newborn neurons, as already shown. ${ }^{14}$ This effect may promote their recruitment and thus contribute to counteract the effects induced by chronic stress. As a matter of fact, the higher proportion of Fos expression in the BrdU + cells, which was found exclusively in UCMS-fluoxetine mice appears to strengthen this interpretation. Another important question is whether or not the effects of newborn neurons during such processes are direct. The fact that Fos expression has been found in BrdU + cells supports this idea. Moreover, newborn granule cells in mice can begin to express glucocorticoid receptor early: $66 \% 1$ week after BrdU integration and almost $100 \%$ four weeks after BrdU integration (as high as older mature neurons). ${ }^{75}$ These data suggest that newborn neurons may potentially be sensitive to glucocorticoid release during their development. However, we did not report any significant change induced by DEX indicating that newborn neurons could actually be 
less sensitive to glucocorticoids than mature neurons. These results are surprising because taken together they indicate that the reduction of the GCL network activation induced by DEX can paradoxically be improved by increasing a population of young neurons though less sensitive to DEX. This apparent discrepancy can be enlightened by a recent study, ${ }^{76}$ where the authors demonstrated that a limited amount of newborn granule cells is able to negatively modulate the activity in the larger population of mature granule cells, maybe by preferentially activating inhibitory interneurons. Accordingly, it is conceivable that, in our context, DEX biases the balance of activity toward young granule cells (if less sensitive to DEX), then potentiating the DEX-induced reduction of the activation of older granule cells. Within this framework, fluoxetine, by enhancing neurogenesis and perhaps improving maturation, might re-establish the sensitivity of the GCL network to novelty/glucocorticoid effects.

The hippocampus is also highly interconnected with various corticolimbic structures, which control the stress response, emotion and motivation such as the amygdala, cingulate gyrus, prefrontal cortex and ventral striatum. ${ }^{16-18}$ These structures are thought to be involved in an integrated stress response and underlie the main pathological manifestations of anxiety/depressive disorders. ${ }^{77-79}$ It is therefore conceivable that the UCMS-induced HPA axis abnormalities represent only a measurable fraction of larger changes in the stress integration system and that elevation of hippocampal neurogenesis might enable monoaminergic antidepressants to strengthen hippocampal influences on these brain regions.

Another important finding of our study is that inhibition of hippocampal neurogenesis does not cause any alteration of the HPA axis functioning or regulation in both control- and UCMS-vehicle mice. The hippocampus is known to contribute to HPA axis regulation: its stimulation can reduce glucocorticoid secretion $^{80,81}$ whereas hippocampal damages can increase stress-induced glucocorticoid release. ${ }^{82,83}$ In spite of this, none of our previous and current results suggest that neurogenesis disruption alone substantially disrupts either the circadian rhythm of HPA axis activity or the stress response. ${ }^{3}$ Defects in hippocampal functioning should therefore require larger alterations in the intrinsic biology of the hippocampus than a neurogenesis decline alone. Accordingly, these results reveal that neurogenesis may not be the driver of the hippocampal regulation on the HPA axis, at least without greater environmental challenges.

Taken together, our data suggest that, while hippocampal neurogenesis would contribute to the improvement of stress integration by antidepressants during chronic stress exposure, its role could be less important in the absence of previous deficiencies or pathological situations. This result parallels the Kempermann's hypothesis of the neurogenic reserve. ${ }^{84}$ He suggests that adult newborn hippocampal neurons would constitute a reserve, inessential in normal conditions, but which could become decisive when the organism is confronted with novelty or complex situations. In our context, new hippocampal neurons might thus be critical for antidepressant effects only when the hippocampus-dependent regulation of the stress system is deficient.

In conclusion, this study demonstrates how hippocampal neurogenesis can contribute to regulate the stress hormone system. This function may explain why adult-generated granule cells are required for several behavioral effects of monoaminergic antidepressants. However, not all the patients with anxiety/depression display HPA axis abnormalities, ${ }^{85}$ as well as not all the mouse strains exhibit HPA axis disturbances following UCMS exposure. ${ }^{45}$ It is therefore likely that the extent of neurogenesis involvement in antidepressant effects can depend on the degree of stress system alterations for each subject or mouse strain. Interestingly, the previous conflicting results can be enlightened by this hypothesis. Indeed, the utilization of control non-stressed mice or stressed mice without any significant alterations of stress systems would be less appropriate to highlight the role of adult-generated hippocampal neurons in antidepressant effects. ${ }^{56,58}$ In the same vein, not all the patients respond to antidepressant therapies; accordingly, extending this work to the mechanisms of what is happening in anxious/depressed patients might be limited to some subtypes of stress-related disorders or subgroups of patients. Future studies will therefore have to examine whether stress system alterations are clearly a condition for the neurogenesis involvement in antidepressant effects and whether adult-generated hippocampal neurons can influence stress integration in other relevant brain regions such as the prefrontal cortex, cingulate cortex or amygdala.

\section{Conflict of interest}

AS, AT, AL, QR, CT, RP and YIV, report no biomedical financial interests or potential conflicts of interests. GG is an employee of Sanofi-Aventis. EDL receives compensation as a consultant to PGxHealth. $\mathrm{RH}$ receives compensation as a consultant for BrainCells, PsychoGenics, Servier, Astra Zeneca and Lundbeck in relation to the generation of novel antidepressants. CB receives compensation as a consultant for Takeda.

\section{Acknowledgments}

We thank Dr Sylvie Chalon (Inserm), Dr Samuel Leman (Université F. Rabelais) for help and comments, Dr Ayumu Tashiro (NTNU) for support as well as Anne-Marie Leguisquet, Séverine Devers, Maryse Pingaud, Dominique Le Glaunec, Lucette Garreau, Edith Klobetz-Rassam, Navieta Ramasami and the PPF 'Analyse des systèmes biologiques' for assistance. AS received research grants from Région Centre, FRM and IBRO, funds from the Bettencourt-Schueller Foundation and is currently supported by the 7 th framework program of the European Commission. EDL is supported by NIH grant K08 MH076083. 


\section{References}

1 Eriksson PS, Perfilieva E, Bjork-Eriksson T, Alborn AM, Nordborg C, Peterson DA et al. Neurogenesis in the adult human hippocampus. Nat Med 1998; 4: 1313-1317.

2 Ming GL, Song H. Adult neurogenesis in the mammalian central nervous system. Annu Rev Neurosci 2005; 28: 223-250.

3 Santarelli L, Saxe M, Gross C, Surget A, Battaglia F, Dulawa S et al. Requirement of hippocampal neurogenesis for the behavioral effects of antidepressants. Science 2003; 301: 805-809.

4 Malberg JE, Eisch AJ, Nestler EJ, Duman RS. Chronic antidepressant treatment increases neurogenesis in adult rat hippocampus. J Neurosci 2000; 20: 9104-9110.

5 Boldrini M, Underwood MD, Hen R, Rosoklija GB, Dwork AJ, John Mann J et al. Antidepressants increase neural progenitor cells in the human hippocampus. Neuropsychopharmacology 2009; 34: 2376-2389.

6 Lucassen PJ, Stumpel MW, Wang Q, Aronica E. Decreased numbers of progenitor cells but no response to antidepressant drugs in the hippocampus of elderly depressed patients. Neuropharmacology 2010; 58: 940-949.

7 Revest JM, Dupret D, Koehl M, Funk-Reiter C, Grosjean N, Piazza $\mathrm{PV}$ et al. Adult hippocampal neurogenesis is involved in anxietyrelated behaviors. Mol Psychiatry 2009; 14: 959-967.

8 Czeh B, Welt T, Fischer AK, Erhardt A, Schmitt W, Muller MB et al. Chronic psychosocial stress and concomitant repetitive transcranial magnetic stimulation: effects on stress hormone levels and adult hippocampal neurogenesis. Biol Psychiatry 2002; 52: 1057-1065.

9 Cameron HA, Gould E. Adult neurogenesis is regulated by adrenal steroids in the dentate gyrus. Neuroscience 1994; 61: 203-209.

10 Gould E, Tanapat P, McEwen BS, Flugge G, Fuchs E. Proliferation of granule cell precursors in the dentate gyrus of adult monkeys is diminished by stress. Proc Natl Acad Sci USA 1998; 95: 3168-3171.

11 Surget A, Saxe M, Leman S, Ibarguen-Vargas Y, Chalon S, Griebel $\mathrm{G}$ et al. Drug-dependent requirement of hippocampal neurogenesis in a model of depression and of antidepressant reversal. Biol Psychiatry 2008; 64: 293-301.

12 Airan RD, Meltzer LA, Roy M, Gong Y, Chen H, Deisseroth K. High-speed imaging reveals neurophysiological links to behavior in an animal model of depression. Science 2007; 317: 819-823.

13 Jiang W, Zhang Y, Xiao L, Van Cleemput J, Ji SP, Bai G et al. Cannabinoids promote embryonic and adult hippocampus neurogenesis and produce anxiolytic- and antidepressant-like effects. I Clin Invest 2005; 115: 3104-3116.

14 Wang JW, David DJ, Monckton JE, Battaglia F, Hen R. Chronic fluoxetine stimulates maturation and synaptic plasticity of adult-born hippocampal granule cells. J Neurosci 2008; 28: 1374-1384.

15 David DJ, Samuels BA, Rainer Q, Wang JW, Marsteller D, Mendez I et al. Neurogenesis-dependent and -independent effects of fluoxetine in an animal model of anxiety/depression. Neuron 2009; 62: 479-493.

16 Floresco SB, Todd CL, Grace AA. Glutamatergic afferents from the hippocampus to the nucleus accumbens regulate activity of ventral tegmental area dopamine neurons. J Neurosci 2001; 21: 4915-4922.

17 Naber PA, Witter MP. Subicular efferents are organized mostly as parallel projections: a double-labeling, retrograde-tracing study in the rat. J Comp Neurol 1998; 393: 284-297.

18 Amaral DG, Witter MP. The three-dimensional organization of the hippocampal formation: a review of anatomical data. Neuroscience 1989; 31: 571-591.

19 Herman JP, Schafer MK, Young EA, Thompson R, Douglass J, Akil $\mathrm{H}$ et al. Evidence for hippocampal regulation of neuroendocrine neurons of the hypothalamo-pituitary-adrenocortical axis. J Neurosci 1989; 9: 3072-3082.

20 Mizoguchi K, Ishige A, Aburada M, Tabira T. Chronic stress attenuates glucocorticoid negative feedback: involvement of the prefrontal cortex and hippocampus. Neuroscience 2003; 119: 887-897.

21 Herman JP, Ostrander MM, Mueller NK, Figueiredo H. Limbic system mechanisms of stress regulation: hypothalamo-pituitary- adrenocortical axis. Prog Neuropsychopharmacol Biol Psychiatry 2005; 29: 1201-1213.

22 Ulrich-Lai YM, Herman JP. Neural regulation of endocrine and autonomic stress responses. Nat Rev Neurosci 2009; 10: 397-409.

23 Rubin RT, Poland RE, Lesser IM, Winston RA, Blodgett AL. Neuroendocrine aspects of primary endogenous depression. I. Cortisol secretory dynamics in patients and matched controls. Arch Gen Psychiatry 1987; 44: 328-336.

24 Nemeroff CB, Widerlov E, Bissette G, Walleus H, Karlsson I, Eklund $\mathrm{K}$ et al. Elevated concentrations of CSF corticotropinreleasing factor-like immunoreactivity in depressed patients. Science 1984; 226: 1342-1344.

25 Holsboer F, von Bardeleben U, Wiedemann K, Muller OA, Stalla GK. Serial assessment of corticotropin-releasing hormone response after dexamethasone in depression. Implications for pathophysiology of DST nonsuppression. Biol Psychiatry 1987; 22: 228-234.

26 Heuser I, Yassouridis A, Holsboer F. The combined dexamethasone/CRH test: a refined laboratory test for psychiatric disorders. J Psychiatr Res 1994; 28: 341-356.

27 Lopez-Duran NL, Kovacs M, George CJ. Hypothalamicpituitary-adrenal axis dysregulation in depressed children and adolescents: a meta-analysis. Psychoneuroendocrinology 2009; 34: 1272-1283.

28 Holsboer-Trachsler E, Stohler R, Hatzinger M. Repeated administration of the combined dexamethasone-human corticotropin releasing hormone stimulation test during treatment of depression. Psychiatry Res 191; 38: 163-171.

29 Appelhof BC, Huyser J, Verweij M, Brouwer JP, van Dyck R, Fliers $\mathrm{E}$ et al. Glucocorticoids and relapse of major depression (dexamethasone/corticotropin-releasing hormone test in relation to relapse of major depression). Biol Psychiatry 2006; 59: 696-701.

30 Kunugi H, Ida I, Owashi T, Kimura M, Inoue Y, Nakagawa S et al. Assessment of the dexamethasone/CRH test as a state-dependent marker for hypothalamic-pituitary-adrenal (HPA) axis abnormalities in major depressive episode: a Multicenter Study. Neuropsychopharmacology 2006; 31: 212-220.

31 Ising M, Horstmann S, Kloiber S, Lucae S, Binder EB, Kern N et al. Combined dexamethasone/corticotropin releasing hormone test predicts treatment response in major depression-a potential biomarker? Biol Psychiatry 2007; 62: 47-54.

32 Datson NA, Speksnijder N, Mayer JL, Steenbergen PJ, Korobko O, Goeman J et al. The transcriptional response to chronic stress and glucocorticoid receptor blockade in the hippocampal dentate gyrus. Hippocampus; doi: 10.1002/hipo.20905 (e-pub ahead of print).

33 Surget A, Wang Y, Leman S, Ibarguen-Vargas Y, Edgar N, Griebel G et al. Corticolimbic transcriptome changes are state-dependent and region-specific in a rodent model of depression and of antidepressant reversal. Neuropsychopharmacology 2009; 34: 1363-1380.

34 Willner P. Validity, reliability and utility of the chronic mild stress model of depression: a 10-year review and evaluation. Psychopharmacology (Berl) 1997; 134: 319-329.

35 Cryan JF, Holmes A. The ascent of mouse: advances in modelling human depression and anxiety. Nat Rev Drug Discov 2005; 4: 775-790.

36 Sibille E, Wang Y, Joeyen-Waldorf J, Gaiteri C, Surget A, Oh S et al. A molecular signature of depression in the amygdala. Am J Psychiatry 2009; 166: 1011-1024.

37 Alonso R, Griebel G, Pavone G, Stemmelin J, Le Fur G, Soubrie P. Blockade of CRF or $\mathrm{V}(1 \mathrm{~b})$ receptors reverses stress-induced suppression of neurogenesis in a mouse model of depression. Mol Psychiatry 2004; 9: 278-286, 224.

38 Paxinos G, Franklin KBJ. The mouse brain in stereotaxic coordinates. Academic Press: San Diego, CA, 2001, 124pp.

39 Snyder JS, Ramchand P, Rabbett S, Radik R, Wojtowicz JM, Cameron HA. Septo-temporal gradients of neurogenesis and activity in 13-month-old rats. Neurobiol Aging; doi:10.1016/ j.neurobiolaging.2009.05.022 (e-pub ahead of print).

40 Snyder JS, Radik R, Wojtowicz JM, Cameron HA. Anatomical gradients of adult neurogenesis and activity: young neurons in the ventral dentate gyrus are activated by water maze training. Hippocampus 2009; 19: 360-370.

41 Seri B, Garcia-Verdugo JM, Collado-Morente L, McEwen BS, AlvarezBuylla A. Cell types, lineage, and architecture of the germinal zone in the adult dentate gyrus. J Comp Neurol 2004; 478: 359-378. 
42 Kempermann G, Gast D, Kronenberg G, Yamaguchi M, Gage FH. Early determination and long-term persistence of adult-generated new neurons in the hippocampus of mice. Development 2003; 130: 391-399.

43 Dayer AG, Ford AA, Cleaver KM, Yassaee M, Cameron HA. Shortterm and long-term survival of new neurons in the rat dentate gyrus. J Comp Neurol 2003; 460: 563-572.

44 Crespo D, Stanfield BB, Cowan WM. Evidence that late-generated granule cells do not simply replace earlier formed neurons in the rat dentate gyrus. Exp Brain Res 1986; 62: 541-548.

45 Ibarguen-Vargas Y, Surget A, Touma C, Palme R, Belzung C. Multifaceted strain-specific effects in a mouse model of depression and of antidepressant reversal. Psychoneuroendocrinology 2008; 33: 1357-1368.

46 Touma C, Palme R, Sachser N. Analyzing corticosterone metabolites in fecal samples of mice: a noninvasive technique to monitor stress hormones. Horm Behav 2004; 45: 10-22.

47 Touma C, Sachser N, Mostl E, Palme R. Effects of sex and time of day on metabolism and excretion of corticosterone in urine and feces of mice. Gen Comp Endocrinol 2003; 130: 267-278.

48 Tashiro A, Makino H, Gage FH. Experience-specific functional modification of the dentate gyrus through adult neurogenesis: a critical period during an immature stage. J Neurosci 2007; 27: $3252-3259$.

49 Kee N, Teixeira CM, Wang AH, Frankland PW. Preferential incorporation of adult-generated granule cells into spatial memory networks in the dentate gyrus. Nat Neurosci 2007; 10: 355-362.

50 Ramirez-Amaya V, Marrone DF, Gage FH, Worley PF, Barnes CA. Integration of new neurons into functional neural networks. J Neurosci 2006; 26: 12237-12241.

51 Henn FA, Vollmayr B. Neurogenesis and depression: etiology or epiphenomenon? Biol Psychiatry 2004; 56: 146-150.

52 Sapolsky RM. Is impaired neurogenesis relevant to the affective symptoms of depression? Biol Psychiatry 2004; 56: 137-139.

53 Eisch AJ, Cameron HA, Encinas JM, Meltzer LA, Ming GL, Overstreet-Wadiche LS. Adult neurogenesis, mental health, and mental illness: hope or hype? J Neurosci 2008; 28: 11785-11791.

54 Duman RS. Depression: a case of neuronal life and death? Biol Psychiatry 2004; 56: 140-145.

55 Meshi D, Drew MR, Saxe M, Ansorge MS, David D, Santarelli L et al. Hippocampal neurogenesis is not required for behavioral effects of environmental enrichment. Nat Neurosci 2006; 9: 729-731.

56 Bessa JM, Ferreira D, Melo I, Marques F, Cerqueira JJ, Palha JA et al. The mood-improving actions of antidepressants do not depend on neurogenesis but are associated with neuronal remodeling. Mol Psychiatry 2009; 14: 764-773, 739.

57 Saxe MD, Battaglia F, Wang JW, Malleret G, David DJ, Monckton JE et al. Ablation of hippocampal neurogenesis impairs contextual fear conditioning and synaptic plasticity in the dentate gyrus. Proc Natl Acad Sci USA 2006; 103: 17501-17506.

58 Holick KA, Lee DC, Hen R, Dulawa SC. Behavioral effects of chronic fluoxetine in BALB/cJ mice do not require adult hippocampal neurogenesis or the serotonin $1 \mathrm{~A}$ receptor. Neuropsychopharmacology 2008; 33: 406-417.

59 American Psychiatric Association. Diagnostic and Statistical Manual of Mental Disorders, $4^{\text {th }}$ edn American Psychiatric Press: Washington DC, 1994.

60 Huang GJ, Bannerman D, Flint J. Chronic fluoxetine treatment alters behavior, but not adult hippocampal neurogenesis, in BALB/CJ mice. Mol Psychiatry 2008; 13: 119-121.

61 Yeragani VK, Pohl R, Mallavarapu M, Balon R. Approximate entropy of symptoms of mood: an effective technique to quantify regularity of mood. Bipolar Disord 2003; 5: 279-286.

62 Gelfin Y, Gorfine M, Lerer B. Effect of clinical doses of fluoxetine on psychological variables in healthy volunteers. Am J Psychiatry 1998; 155: 290-292.

63 Barr LC, Heninger GR, Goodman W, Charney DS, Price LH. Effects of fluoxetine administration on mood response to tryptophan depletion in healthy subjects. Biol Psychiatry 1997; 41: 949-954.
64 Vollmayr B, Simonis C, Weber S, Gass P, Henn F. Reduced cell proliferation in the dentate gyrus is not correlated with the development of learned helplessness. Biol Psychiatry 2003; 54: 1035-1040.

65 Zhao C, Deng W, Gage FH. Mechanisms and functional implications of adult neurogenesis. Cell 2008; 132: 645-660.

66 Wong ML, Licinio J. Research and treatment approaches to depression. Nat Rev Neurosci 2001; 2: 343-351.

67 Schloesser RJ, Manji HK, Martinowich K. Suppression of adult neurogenesis leads to an increased hypothalamo-pituitary-adrenal axis response. Neuroreport 2009; 20: 553-557.

68 Treves A, Tashiro A, Witter ME, Moser EI. What is the mammalian dentate gyrus good for? Neuroscience 2008; 154: 1155-1172.

69 Becker S, Wojtowicz JM. A model of hippocampal neurogenesis in memory and mood disorders. Trends Cogn Sci 2007; 11: 70-76.

70 Wang S, Scott BW, Wojtowicz JM. Heterogenous properties of dentate granule neurons in the adult rat. $J$ Neurobiol 2000; 42: 248-257.

71 Snyder JS, Kee N, Wojtowicz JM. Effects of adult neurogenesis on synaptic plasticity in the rat dentate gyrus. J Neurophysiol 2001; 85: $2423-2431$.

72 Ge S, Yang CH, Hsu KS, Ming GL, Song H. A critical period for enhanced synaptic plasticity in newly generated neurons of the adult brain. Neuron 2007; 54: 559-566.

73 Schmidt-Hieber C, Jonas P, Bischofberger J. Enhanced synaptic plasticity in newly generated granule cells of the adult hippocampus. Nature 2004; 429: 184-187.

74 Laplagne DA, Esposito MS, Piatti VC, Morgenstern NA, Zhao C, van Praag $\mathrm{H}$ et al. Functional convergence of neurons generated in the developing and adult hippocampus. PLoS Biol 2006; 4: e409.

75 Garcia A, Steiner B, Kronenberg G, Bick-Sander A, Kempermann G. Age-dependent expression of glucocorticoid- and mineralocorticoid receptors on neural precursor cell populations in the adult murine hippocampus. Aging Cell 2004; 3: 363-371.

76 Lacefield CO, Itskov V, Reardon T, Hen R, Gordon JA. Effects of adultgenerated granule cells on coordinated network activity in the dentate gyrus. Hippocampus; doi: 10.1002/hipo.20860 (e-pub ahead of print).

77 Seminowicz DA, Mayberg HS, McIntosh AR, Goldapple K, Kennedy $\mathrm{S}$, Segal Z et al. Limbic-frontal circuitry in major depression: a path modeling metanalysis. Neuroimage 2004; 22: 409-418.

78 Drevets WC, Price JL, Furey ML. Brain structural and functional abnormalities in mood disorders: implications for neurocircuitry models of depression. Brain Struct Funct 2008; 213: 93-118.

79 Carlson PJ, Singh JB, Zarate Jr CA, Drevets WC, Manji HK. Neural circuitry and neuroplasticity in mood disorders: insights for novel therapeutic targets. NeuroRx 2006; 3: 22-41.

80 Rubin RT, Mandell AJ, Crandall PH. Corticosteroid responses to limbic stimulation in man: localization of stimulus sites. Science 1966; 153: 767-768.

81 Dunn JD, Orr SE. Differential plasma corticosterone responses to hippocampal stimulation. Exp Brain Res 1984; 54: 1-6.

82 Herman JP, Cullinan WE, Morano MI, Akil H, Watson SJ. Contribution of the ventral subiculum to inhibitory regulation of the hypothalamo-pituitary-adrenocortical axis. J Neuroendocrinol 1995; 7: 475-482.

83 Sapolsky RM, Krey LC, McEwen BS. Glucocorticoid-sensitive hippocampal neurons are involved in terminating the adrenocortical stress response. Proc Natl Acad Sci USA 1984; 81: 6174-6177.

84 Kempermann G. The neurogenic reserve hypothesis: what is adult hippocampal neurogenesis good for? Trends Neurosci 2008; 31: 163-169.

85 Holsboer F. The corticosteroid receptor hypothesis of depression. Neuropsychopharmacology 2000; 23: 477-501.

(c) This work is licensed under the Creative Commons Attribution-NonCommercialShare Alike 3.0 Unported License. To view a copy of this license, visit http://creativecommons.org/ licenses/by-nc-sa/3.0/

Supplementary Information accompanies the paper on the Molecular Psychiatry website (http://www.nature.com/mp) 